Military Technical College

Kobry Elkobbah, Cairo,

Egypt.

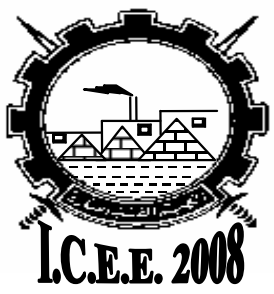

$4^{\text {th }}$ International Conference On Chemical \& Environmental Engineering

27-29 May 2008

\title{
ADSORPTION OF HEAVY METALS FROM AQUEOUS SOLUTIONS ONTO SILICA EXTRACTED FROM AGRO-RESIDUES IN SINGLE ZN, CU AND NI SYSTEMS.
}

\author{
H. A. Hanafi ${ }^{*}$, S. A. Kandil* and A. A. M. Daifullah ${ }^{* *}$
}

\begin{abstract}
Single Zinc, Nickel and cadmium adsorption from aqueous solution onto silica extracted from agro-residue is reported. and is consider a low cost method for recovery of $\mathrm{Zn}$ and $\mathrm{Cd}$ in the production of $\mathrm{Ga}-67$ and $\mathrm{In}-111$ isotopes in Egypt's Cyclotron and also solve environmental problem from burning of rice husks. The dependence adsorption on contact time, adsorbent type and adsorption medium and also $\mathrm{pH}$ was investigated showing that there is a difference in minimum contact time for different metal ions and the mechanism of adsorption of metal ions on silica extracted from rice husks were also studied. Therefore, silica extracted from rice husk is considered as a better replacement technology for recovery of enriched zinc and cadmium were used in preparation of targets for ${ }^{67} \mathrm{Ga}$ and ${ }^{111} \mathrm{In}$ production due to low cost and good efficiency in this application.
\end{abstract}

\section{KEYWORDS:}

Adsorption ; heavy metals; Rice husk; Recovery; Silica.

\section{NOMENCLATURE:}

RP-1: Activated carbon with $1 \% \mathrm{KOH}$

RP-5: Activated carbon with $5 \% \mathrm{KOH}$

RS-5: Silica extracted from rice husks

ACRH: Activated carbon prepared from rice hulls

\footnotetext{
Cyclotron project, Nuclear Research Center, Atomic Energy Authority, Abu-Zabal-Kalubia, Egypt , Egypt, P. O. 13759. E-mail: Hassanhanfi@hotmail.com

** Hot Laboratory Centre, Analytical Chemistry Department, Atomic Energy Authority, Abu-ZabalKalubia, Egypt. E-mail: Hassanhanfi@hotmail.com
} 


\section{INTRODUCTION}

In the past few years there has been a manifest interest in the adsorption process in solution because these processes play an important role in phenomena such as the environmental transport of heavy metals [1-2], analytical separations [3] and preconcentration of metals present in trace amounts [4]. With the increase in the number of nuclear power reactors, the radioactive pollution of water is growing, this problem could be alleviated by means of suitable adsorption processes, and also activated carbons are used extensively as adsorbents of different compounds [5].

It has been shown that activated carbons obtained from agricultural by-products such as olive stones [6] and almond shells [7] can be favorably compared with other activated carbons used in industry with respect to their adsorptive properties. Factors affecting the adsorption process e.g. $\mathrm{pH}$, activated carbon dosage, contact time, initial metal concentration and solution temperature were studied [8]. Single copper and nickel adsorption from aqueous solutions onto a granular activated carbon were reported, metals removal increase on raising $\mathrm{pH}$ and temperature, and decrease on raising the initial concentration at constant carbon dose, the adsorption processes were modeled using the Surface Complex Formation (SCF), Triple Layer Model (TLM) [9]. Zinc is an essential trace element, but a large concentration of zinc in biological system can prove to be toxic [10].

The removal of toxic metal ions from dilute or concentrated solutions has received a great deal of attention in the last few decades. In recent years, stringent statutory regulations have been introduced to reduce the discharge of toxic metals to low level at source, particularly from metal processing industries. This has been partially achieved by minimization and recycling of existing resources. With the increasing demand for cleaner water, attention has been focused on improvements to existing treatments and the development of new techniques and materials. The removal of metal contaminants from effluent streams has the advantage of reducing the cost of waste disposal. In most cases, the treatment of waste water gives rise to secondary effluents. Efficiency of such process can be improved by recycling treated water and / or metal recovery. General methods applied to the removal of metals include ion exchange [11] or adsorption [11, 12], precipitation [13, 14], floatation [15], evaporation [16, 17] and membrane processes [18]. By using ion exchange and adsorption most of the water can be recycled without the need for further treatment. In some cases, the metal can also be recovered in a useful form.

A variety of materials have been investigated for the removal of metals from metallurgical effluents. Conventional activated carbons are extensively used in water treatment for removal of color, odor and organic contaminants [19]. These carbonaceous materials posses the potential for removal of inorganic species from effluent streams. Activated carbons are of high porosity, high surface area materials and are prepared from readily available carbonaceous precursors. These precursors are normally exposed to a number of different activation methods in an effort to achieve an activated carbon with the most favorable properties for a particular application. 
The texture of activated carbons may be adopted to suit the situation by adequate choice of the activation procedure. The nature and concentration of the surface functional groups may be modified by suitable thermal or chemical post-treatments. Introduction of oxygen-containing groups not only improves the cationic uptake capacity of the precursor but it also makes the surface more hydrophilic amenable to wetting.

It has been shown that, for adsorption of inorganic compounds on activated carbons from aqueous solutions, the chemical nature of the adsorbent determined by the amount and the nature of the surface complexes has in general more influence than the surface area and porosity of adsorbent [20]. Removal of metals by conventional activated carbons has been studied by a number of authors [21]. In general, ordinary activated carbons posses large surface areas but have a relatively low capacity for metal ions. Modified activated carbons have been examined as alternatives to conventional polymeric ion exchange resins. The ion exchange reactivity of oxidized carbon for the removal of copper, zinc and nickel from solution is reported [22]. Others have also reported for removal of other cations by oxidized activated carbons $[23,24]$.

DACRO (12-20 mesh) has been investigated. This type of carbon is an effective adsorbent for both metals (cadmium and zinc). The adsorptive capacity increased by increasing $\mathrm{pH}$ and decreased with molar metal/carbon ratio, the adsorption process has been modeled using the Triple Layer Model (TLM).

The presence of priority pollutants, such as cadmium, in the effluent streams from several chemicals and metal plating industries has been a major environmental problem for both industries and neighboring municipalities. The removal of copper (II) and cadmium (II) ions from aqueous solutions, by adsorption on activated carbon prepared from rice hulls $(\mathrm{ACRH})$ was investigated, it was found that it depends on $\mathrm{pH}$, activated carbon dosage, contact time, initial metal concentration and solution temperature.

\section{EXPERIMENTAL}

\subsection{Materials}

Rice husk (was found in Cairo, Egypt) was chosen as a precursor material for preparation of interesting sorbent. In this concern, $25 \mathrm{~g}$ of raw material was soaked in a sufficient amount of $5 \%(\mathrm{KOH})$ to cover the raw material completely. Slightly agitated and boiled for $30 \mathrm{~min}$ and left overnight was carried out. The impregnated solid was filtered. The filtrate was washed twice with distilled water (200 $\mathrm{ml}$ each). Then, about $400 \mathrm{ml}$ of $10 \% \mathrm{HCl}$ was added until the $\mathrm{pH}$ reached 5 and the formed precipitate. 


\section{1. 1. Preparation of Various Sorbents.}

It is well known that silica dissolves in hot alkali hydroxides forming orthosilicate and water as follows:

$$
\mathrm{SiO}_{2}+4 \mathrm{OH}^{-} \rightarrow 2 \mathrm{H}_{2} \mathrm{O}+\mathrm{SiO}_{4}^{4-} \quad \text { (orthosilicate) }
$$

The formed silicate decomposed by acid $(\mathrm{HCl})$ with prceipitation of silica $\left(\mathrm{SiO}_{2}\right)$. Accordingly, it was possible to prepare two series of sorbents.

This work aims to the full exploitation of the raw material by separation of its miscellaneous components through alkali treatment. The residual carbonaceous component is converted into activated carbon by the steam pyrolysis scheme. The leached silica is precipitated as silica gel by low strength acidification whereby a binary (or twin) adsorbents are produced Fig. 1 ..

Schematic presentation for the preparation of various adsorbents

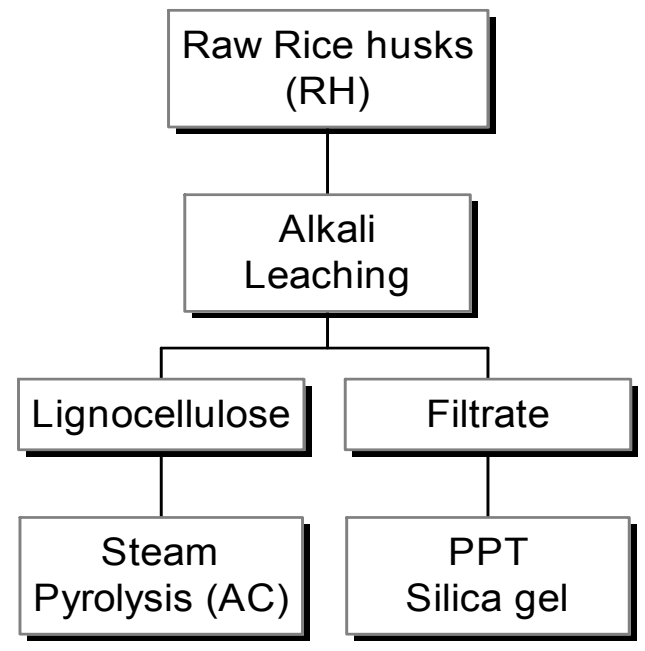

\section{1. 1. 1. Steam Activated Carbons from Alkaline Treated Rice Husk.}

Raw $\mathrm{RH}$ was stirred with the concentration of 1,3 and $5 \% \mathrm{KOH}$ and heated to boiling for $30 \mathrm{~min}$, then the mixture was left overnight, filtered and washed twice with distilled water until filtrate became neutral, and finally the residue was dried at $110{ }^{\circ} \mathrm{C}$. Then, the dry residue was placed in the reactor and immersed in the hot zone of the tubular furnace. The temperature was raised gradually $\left(50{ }^{0} \mathrm{C} / 10 \mathrm{~min}\right.$.), to allow free evolution of volatiles, up to around $350{ }^{\circ} \mathrm{C}$. Pure steam was then introduced to the heated mass, and heating was continued up to a standard temperature of $650{ }^{\circ} \mathrm{C}$. The products were soaked at this temperature for $1 \mathrm{hr}$, and then cooled and the weight was determined. The produced activated carbons take the abbreviations: RP-1 and RP-5. 


\section{1. 1. 2. Silica Extracted from Rice Husk by Alkaline Treatment.}

The filtrate from the above alkaline-treated $\mathrm{RH}$ was collected, and subsequently used, as it is predicted to contain leached silica the major component of the ash. To the filtrate, $10 \% \mathrm{HCl}$ was added so as to precipitate dissolved silica, until the $\mathrm{pH}$ reached (5-7), a white precipitate was formed, which was filtered, dried and weighed RS-5.

\section{2. Chemicals and Instrumentation}

\section{1. 2. Chemicals and Reagents.}

All the solutions used in this study were prepared from analytical reagent grade chemicals, and double distilled water was used throughout this work for solutions preparation as well as for final washing of the glass wires. The stock solution of adsorbates was prepared by dissolving the required amount of the pure reagent in a least amounts of bidistilled water, and then transferring to a volumetric flask and completing to the mark with double distilled water.

\subsection{Batch Experiments.}

Batch experiments were conducted by mixing $10 \mathrm{ml}$ solutions, containing metals with a constant dose of adsorbent $(20 \mathrm{mg})$ in $100 \mathrm{~cm}^{3}$ Pyrex Erlenmeyer flasks with caps. Flasks were shaken $(180 \mathrm{rpm})$ at constant temperature using a new Brunswick Scientific G25KC model incubator orbital shaker with temperature control. Various periods of agitation were employed to determine the minimum contact time required for complete or maximum metal adsorption and also $\mathrm{pH}$ effect were done and measured by a WTW combined electrode $\mathrm{pH}$ meter, model 3000 , equipped with a temperature probe. For separation of $\mathrm{Zn}, \mathrm{Cd}$ and $\mathrm{Ni}$ it is necessary to determine the distribution coefficient. A stock solution of the $1000 \mathrm{mg} / \mathrm{l}$ Zinc, $100 \mathrm{mg} / \mathrm{l}$ cadmium and $100 \mathrm{mg} / \mathrm{l}$ nickel was prepared by dissolving in a hot concentration $\mathrm{HCl}$. The solution was evaporated to incipient dryness, and the residue dissolved in $100 \mathrm{ml}$ of double distilled water. To $1 \mathrm{ml}$ of this solution $9 \mathrm{ml}$ different concentrations of $\mathrm{HCl}$ or other medium such as $00.01 \mathrm{M} \mathrm{NH}_{4} \mathrm{Cl}$ at variable $\mathrm{pH}$ was added to a fixed weight of sorbent (50 mg). The contents were shaken for $30 \mathrm{~min}$ to attain equilibrium. The two phases (solid and liquid) were separated. The distribution coefficient $\left(\mathrm{K}_{\mathrm{d}}\right)$ was obtained by employing the formula in 1947. For all batch experiments determination of zirconium and yttrium concentrations will be measured by using inductively coupled plasma optical emission spectrometry (ICP-OES) using the system ULTIMA-2 ICP, Jobin Yvon, France.

\section{RESULTS AND DISCUSSIONS}

This part deals with the factors affecting sorption of $\mathrm{Zn}^{+2}, \mathrm{Cd}^{+2}$ and $\mathrm{Ni}^{+2}$ in singlecomponent system in batch mode. These factors are: adsorbent type, shaking time, $\mathrm{pH}$, sorption medium type, sorption medium molarity, adsorbent weight. 


\section{1. Batch Mode (Single-Component Systems).}

The factors affecting sorption of zinc, cadmium and nickel (as adsorbent type, shaking time, type of matrix, matrix molarity, adsorbent weight.

\section{1. 1. Sorbent Selection.}

\section{1. 1. 1. Zinc Adsorption.}

The result of the tests to evaluate the ability of the 3-sorbents (RP-1, RP-5 and RS-5) to adsorb zinc from $0.01 \mathrm{M} \mathrm{HCl}$ solutions at different time intervals are shown in Fig. 2. Sorbent RS-5 was determined to be superior, it is a silica-based sorbent. As shown in Fig. 2., the uptake order is RS-5> RP-5 > RP-1 in $0.01 \mathrm{M} \mathrm{HCl}$. This means that the adsorptive capacity of RS-5 is twice than that of RP-1 and slightly higher than RP-5.

Figs. 3. and 4. show the effect of sorbent type on the uptake of zinc at $0.1 \mathrm{M}$ and $1 \mathrm{M}$ $\mathrm{HCl}$, respectively. It was clear that the adsorptive capacity of zinc using RS-5 increases as the acid molarity decreases. Similar results are obtained for the two sorbents RP-1 and RP-5. This means that the uptake of zinc is maximum at $0.01 \mathrm{M}$ $\mathrm{HCl}$ using RS-5.

\section{1. 1. 2. Cadmium Adsorption.}

Fig. 5. demonstrates the adsorptive capacity of $\mathrm{Cd}^{+2}$ by the three sorbents under investigation (RS-5, RP-5 and RP-1) at different time intervals using $0.01 \mathrm{M} \mathrm{HCl}$ solutions. It was clear that the RS-5 sorbent gives the maximum uptake in $0.01 \mathrm{M}$ $\mathrm{HCl}$ solutions. The capacity of RS-5 is more than two folds and a half compared to the capacity of RP-1 and is greater than one and a half of the capacity of RP- 5 . Similar trend was observed as shown in Figs. 6. and 7. for the uptake of $\mathrm{Cd}^{+2}$ in various acid molarities using the three sorbents under investigations. This can be explained by the variation of matrix $\mathrm{pH}$ and consequently the solute species in solution.

\section{1. 1. 3. Nickel Adsorption.}

Figs. 8., 9. and 10. illustrate the results of the adsorptive capacity of nickel by the three sorbents (RP-1, RP-5 and RS-5) in 0.01, 0.1 and $1 \mathrm{M} \mathrm{HCl}$ at different shaking time periods, respectively. It was clear that the difference in uptake is small by the three sorbents in various acid molarities. This may be due to the initial concentration of solute is low. Since, the purpose of these experiments not only to determine the highest adsorptive capacity of $\mathrm{Ni}$ ions but also to decide the uptake value at this initial concentration using the three sorbents (RP-1, RP-5 and RS-5) to overcome the recovery problem of the enriched targets $\left(\mathrm{Zn}^{+2}\right.$ and $\left.\mathrm{Cd}^{+2}\right)$ in presence of $\mathrm{Ni}$. So, it is interesting, however, to note the second face of the coin. i.e. It is useful to use the best adsorbent which achieve the maximum adsorptive capacity for target metal ions $\left(\mathrm{Zn}^{+2}\right.$ and $\left.\mathrm{Cd}^{+2}\right)$ and the minimum capacity of any interfering ions e.g. $\mathrm{Ni}^{+2}$. That is 


\section{1. 2. Minimum Contact Time of Zinc.}

As shown in Fig. 11. the uptake capacity increased from $132 \mathrm{mg} / \mathrm{g}$ to $204 \mathrm{mg} / \mathrm{g}$ by decreasing the molarity of acid $(\mathrm{HCl})$ from $1 \mathrm{M}$ to $0.01 \mathrm{M}$. i.e. the uptake capacity increased by 72 or $42 \mathrm{mg} / \mathrm{g}$ by reducing the acid molarity 100 or 10 times, respectively. Again, the equilibrium time between zinc ions and the sorbent RP-1 at the different acid molarities $(0.01,0.1$ and $1 \mathrm{M})$ remains constant and reaches steady state or equilibrium after 8 hours i.e. The equilibrium time is independent on the molarity of the matrix.

Fig. 12. prove that the equilibrium contact time is independent on the acid molarity and it reaches after 8 hours of contact between the RP- 5 and $\mathrm{Zn}$ ions. As shown in Fig. 13., the equilibrium time attains its steady state condition after 5 hours of contact between the RS-5 and $\mathrm{Zn}$ ions. In spite of the kinetic of RS-5: $\mathrm{Zn}^{+2}$ adsorption system is faster than both RP-5 : $\mathrm{Zn}^{+2} \mathrm{RP}-1: \mathrm{Zn}^{+2}$, the capacity of the former is better than the latter. In this concern, the adsorptive capacity increased by $30 \mathrm{mg} / \mathrm{g}$ (from 320 to $350 \mathrm{mg} / \mathrm{g}$ ) by a reduction of the acid molarity from $5 \mathrm{M}$ to $1 \mathrm{M} \mathrm{HCl}$. Whereas the capacity increased by $54 \mathrm{mg} / \mathrm{g}$ (from 350 to $404 \mathrm{mg} / \mathrm{g}$ ) by a reduction of the acid molarity 100 times (from $1 \mathrm{M}$ to $0.01 \mathrm{M}$ ). This reveals that the increase of the capacity does not linearly proportional to the decrease of the acid molarity. This is logic because the adsorptive capacity depends mainly on the textural properties of sorbent and the metal species on the solution. The increase in the amount of zinc adsorbed due to the molarity of acid decreases can be explained as the molarity of acid increase, $\mathrm{pH}$ of the solution decreases, and this variation in the extent of amount adsorbed with $\mathrm{pH}$ can be explained based on the nature of zinc species present in the solution and the surface properties of the adsorbent in the presence of the adsorptive solution as shown in the following:

$\mathrm{Zn}^{+2}$ (aq.) $+\mathrm{H}_{2} \mathrm{O} \leftrightarrow[\mathrm{Zn}(\mathrm{OH})]^{+}$(aq.) $+\mathrm{H}^{+}$(aq.) $\quad \mathrm{pK}=9.25$

The effect of sorption medium type on the equilibrium contact time using sorbent RS5 was presented by the two Figs. 13. and 14. It was clear that the equilibrium time independent on the molarity of sorption medium. The impact of matrix type was clearly identified. As shown in Fig. 14., as the concentration of $\mathrm{NH}_{4} \mathrm{Cl}$ increases, the adsorptive capacity increases too. The situation is opposite using $\mathrm{HCl}$. Fig. 13. by the same sorbent (RS-5). This is logic, considering the predominant species are mainly $\mathrm{Zn}^{+2}$ which can interact with silanol groups of solid surface through cation exchange to a certain limit of acid molarity. But, at high concentration of the $\mathrm{HCl}$, the cation exchange reaction is retarded due to $\mathrm{H}^{+}$of the silanol group has great resistance to carry out the simple cation exchange on the surface complexation reaction due to excess $\mathrm{H}^{+}$comes from $\mathrm{HCl}$ at high molarity.

$$
\mathrm{HCl} \rightarrow \mathrm{H}^{+}+\mathrm{Cl}^{-} \quad \text { (strong electrolyte) }
$$


This causes a reduction in the adsorption capacity at high acid molarity. The same interpretation can prove the high capacity at high concentration of $\mathrm{NH}_{4} \mathrm{Cl}$.

$$
\mathrm{NH}_{4} \mathrm{Cl} \rightarrow \mathrm{NH}_{4}^{+}+\mathrm{Cl}^{-} \quad \text { (weak electrolyte) }
$$

In this concern, the predominant species are $\mathrm{Zn}^{+2}$ and $\mathrm{Zn}(\mathrm{OH})^{+}$. The available $\mathrm{Cl}^{-}$ ions given off by the weak electrolyte tend to associate with an equivalent number of protons in acidic range, forming an "ion-pair", the remaining positively charged $\mathrm{NH}_{4}{ }^{+}$ enhances in an indirect way the simple cation exchange between the metal species and the proton of the silanol group.

It was clear that, for RP-5: $\mathrm{Zn}^{+2}$ and RS-5: $\mathrm{Zn}^{+2}$ adsorption systems, 8 and 5 hours are enough time to attain equilibrium for both systems respectively. This means that the equilibrium steady state conditions depend on the sorbent type. In conclusion, it is reasonable to decide that the equilibrium of $\mathrm{Zn}^{+2}$ depends on the sorbent type and sorption medium type and independent on the molarity of the sorption medium.

\section{1. 3. Minimum Contact Time of Cadmium.}

The data of the equilibrium time of $\mathrm{Cd}^{+2}$ ions using the three sorbents (RP-1, RP- 5 and $\mathrm{RS}-5)$ in the two sorption mediums $\left(\mathrm{HCl}\right.$ and $\left.\mathrm{NH}_{4} \mathrm{Cl}\right)$ were presented in Figs. 15., 16., 17. and 18.. it was clear that, the minimum contact time reaches the equilibrium state after 6 hours in case of using (RP-1 and RP-5) and 4 hours in case of using RS-5 which is silica based. This means that the kinetics of Cd : RS-5 adsorption system is faster than the other two systems. As shown in Fig. 15., the equilibrium steady state conditions did not differ at various acid molarities $(0.01,0.1$ and $1 \mathrm{M})$, i.e. The equilibrium time is independent on the molarity of matrix used. These data is confirmed by using sorbent RP-5 and RS-5 as shown in Figs. 16. and 17., respectively.

Generally, it is worth to mention that the equilibrium contact time in case of cadmium adsorption is less than the case of zinc adsorption. This means that the adsorption kinetics of cadmium is faster than that of zinc and this may be referred to the adsorption rate for each adsorption system.

The matrix type effect is illustrated by using the sorbent RS-5 at different molarities of $\mathrm{HCl}(0.01,0.1,1$ and $5 \mathrm{M})$ and different molarities of $\mathrm{NH}_{4} \mathrm{Cl}(0.01,0.1$ and $1 \mathrm{M})$, as shown in Fig. 17. and 18., respectively, it was clear that the equilibrium state is same in both sorption mediums. The adsorptive capacity is increased by decreasing acid molarity and by increasing $\mathrm{NH}_{4} \mathrm{Cl}$ molarity. This inverse action of sorption medium type on the adsorptive capacity for cadmium ions by sorbent (RS-5) may be referred to the cadmium species as well as the sorption medium type present in solution.

$\mathrm{Cd}^{+2}+\mathrm{H}_{2} \mathrm{O} \leftrightarrow \mathrm{Cd}(\mathrm{OH})^{+}+\mathrm{H}^{+} \quad \mathrm{pK}=9.00$ 
The acid protons $\mathrm{H}^{+}$, control the direction of cadmium species and thus $\mathrm{Cd}^{+2}$ is the predominant in case of acid medium. Consequently, simple cation exchange with the surface silanol group Si-OH may be occur. This is the case at low acid molarity. In case of higher molarity, the excess $\mathrm{H}^{+}$affects the exchange process and retards the deprotonation of silanol group and thus the adsorptive capacity decreases as acid molarity increases. In case of using $\mathrm{NH}_{4} \mathrm{Cl}, \mathrm{Cd}^{+2}$ and $\mathrm{Cd}(\mathrm{OH})^{+}$remain in comparable amounts and the deprotonation of silanol groups is enhanced especially at high molarity and consequently the adsorptive capacity increases as the sorption medium molarity decreases.

\section{1. 4. Minimum contact time of nickel.}

The results of the tests to evaluate the minimum contact time for the three adsorption systems are described in Figs. 19., 20. and 21. In this concern, the amount adsorbed $(\mathrm{mg} / \mathrm{g})$ on the ordinate versus the shaking time $(\mathrm{h})$ on the abscissa are plotted for the three adsorption systems $\mathrm{Ni}^{+2}$ : RP-1; $\mathrm{Ni}^{+2}$ : RP-5 and $\mathrm{Ni}^{+2}$ : RS-5 using different molarities of $\mathrm{HCl}$ in Figs. 19., 20. and 21. respectively. As shown in Fig. 19, the equilibrium time reaches after 6 hours of contact between nickel ions and sorbent RP-1, whereas the equilibrium attains after 2 hours using RP-5 and 15 min. using RS- 5 sorbent, respectively. This means that the minimum contact time is given in $\mathrm{Ni}^{+2}$ : RS-5 adsorption system even various molarities of $\mathrm{HCl}$ were used.

To decide the effect of sorption solution type on the equilibrium time, further experiments were done on $\mathrm{Ni}^{+2}$ : RS-5 adsorption system using $\mathrm{NH}_{4} \mathrm{Cl}$ at different molarities $(0.01,0.1$ and $1 \mathrm{M}$ ), as shown in Fig. 22. The results prove that $15 \mathrm{~min}$. was sufficient time to reach the steady state conditions and the amount adsorbed increases as the molarity of $\mathrm{NH}_{4} \mathrm{Cl}$ decreases.

In conclusion, it is worth to mention that the sorbent RS-5, which is mainly silica, is the best for kinetic considerations when $\mathrm{NH}_{4} \mathrm{Cl}$ used as sorption medium and this observation is the key for the recovery conditions.

\section{1. 5. Effect of pH.}

The $\mathrm{pH}$ of the solution is one of the most important factors in the study of the adsorption of metal ions on solids. This effect is important for various reasons, namely;

(1) The state of metal ions in solution strongly depends on the $\mathrm{pH}$ and the adsorbability of different forms of metal ions usually differ,

(2) The $\mathrm{pH}$ can substantially affect the surface electric charge of the adsorbent, which is important for the electrostatic adsorption of ions and colloids,

(3) $\mathrm{H}_{3} \mathrm{O}^{+}$and $\mathrm{OH}^{-}$ions can compete with metal ions and the extent of the competition depends on the acidity of hydrogen and hydroxide ions,

(4) The acidity and basicity of the solution can influence, the composition and the properties of the adsorbent surface and

(5) Anions of acid or cations of the base used for $\mathrm{pH}$ adjustment can additionally compete with metal ions. 
For these reasons, the $\mathrm{pH}$ dependence of metal ion adsorption is a complex phenomenon and influences the metal uptake by solids. For this reason, the adsorption behavior of $\mathrm{Zn}^{+2}, \mathrm{Cd}^{+2}$ and $\mathrm{Ni}^{+2}$ ions were studied within the limited range of $\mathrm{pH}$. The data on the effect of $\mathrm{pH}$ showed that the adsorption of all the metal ions studied was markedly influenced by the solution pH, Figs. 23, 24. and 25 . There was a rapid increase in metal ion adsorption on increasing acid molarity (decrease $\mathrm{pH}$ ) and the adsorption decreased as the molarity of $\mathrm{NH}_{4} \mathrm{Cl}$ increased.

\section{1. 5. 1. Mechanism of adsorption.}

According to the simple species diagrams which were constructed for $\mathrm{Zn}^{+2}, \mathrm{Cd}^{+2}$ and $\mathrm{Ni}^{+2}$ ions respectively, all the species occurring at $\mathrm{pH}$ values of 7.0 and below carry a positive charge as $\mathrm{Zn}^{+2}, \mathrm{Zn}(\mathrm{OH})^{+}, \mathrm{Cd}^{+2}, \mathrm{Cd}(\mathrm{OH})^{+}$and $\mathrm{Ni}^{+2}, \mathrm{Ni}(\mathrm{OH})^{+}$. In this case adsorption occurs by electrostatic attraction. The increase in adsorption with increase of $\mathrm{pH}$ may also be explained on the basis of aqua complex formation of the oxides present in the ash of RS-5 and its subsequent acid-base dissociation at the solidsolution interface. The $\mathrm{SiO}_{2}$ found on the surface of $\mathrm{RS}-5$ particles in significant quantities (94.5\%) from total ash content according to the elemental analysis of RS5. The silica $\left(\mathrm{SiO}_{2}\right)$ in RS-5 could adsorb either positive or negative contaminants depending on the $\mathrm{pH}$ of the solution. The central ion of silicates has an electron affinity, giving the oxygen atoms bound to it low basicity. This allows the silica surface to act as a weak acid, which can react with water, forming surface silanol $(\mathrm{SiOH})$ groups. As a result, at low $\mathrm{pH}$ the silica is positively charged and at high $\mathrm{pH}$ values it is negatively charged. The $\mathrm{pH}_{\mathrm{ZPC}}$ of silica is generally in the neighborhood of 2.0. The effect of $\mathrm{pH}$ on the charge at the surface of silica.

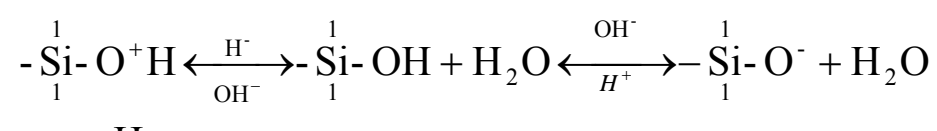

$\mathrm{H}$

Positive Surface PZC Negative Surface

The surface hydroxyl groups of silica (silanol and disilanol groups) can function as donors of a proton and a hydroxyl, forming a negative and a positive site on the surface respectively. Hence, when silica is brought in contact with metal solutions both cation and anion exchange can take place, the former being favoured at higher $\mathrm{pH}$ and the latter at lower $\mathrm{pH}$. However, the main constituents of the sorbent RS-5 are C $37.5 \%$ and ash $20.5 \%$. Hence, the sorption process may occur not only by ion exchanging but also due to the presence of carbon at the surface of the sorbent.

There are two major types of chemical bonding can be responsible for the adsorption of various metal ions onto activated carbon (RS-5) surface: covalent bonding and hydrogen bonding. The covalent bonding results from the sharing of free electron pairs between the surface oxygen atom and the metal atom or the formation of an $\mathrm{O}$ ---M bonding. 


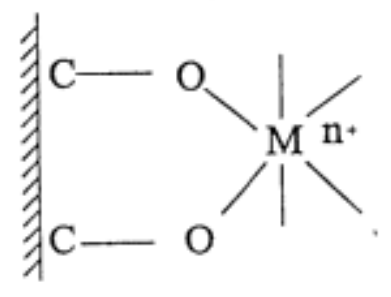

I



III

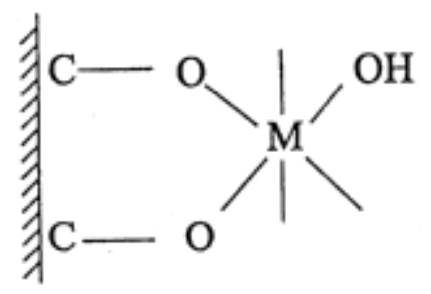

II

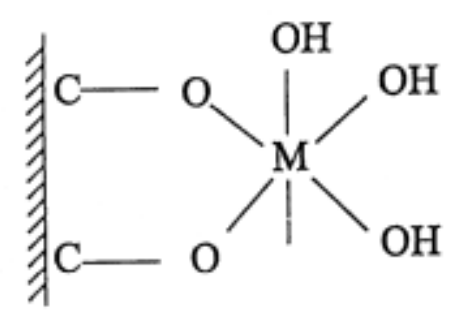

IV

The hydrogen bonding results from the long - range force between surface oxygen atom and the hydrogen atom of the hydrated metal ions. Covalent bonding produces inner-sphere complexes, whereas, the hydrogen bonding produces outer -sphere complexes. Under the currently available experimental results, it is not possible to differentiate the exact nature of these two adsorption mechanisms.
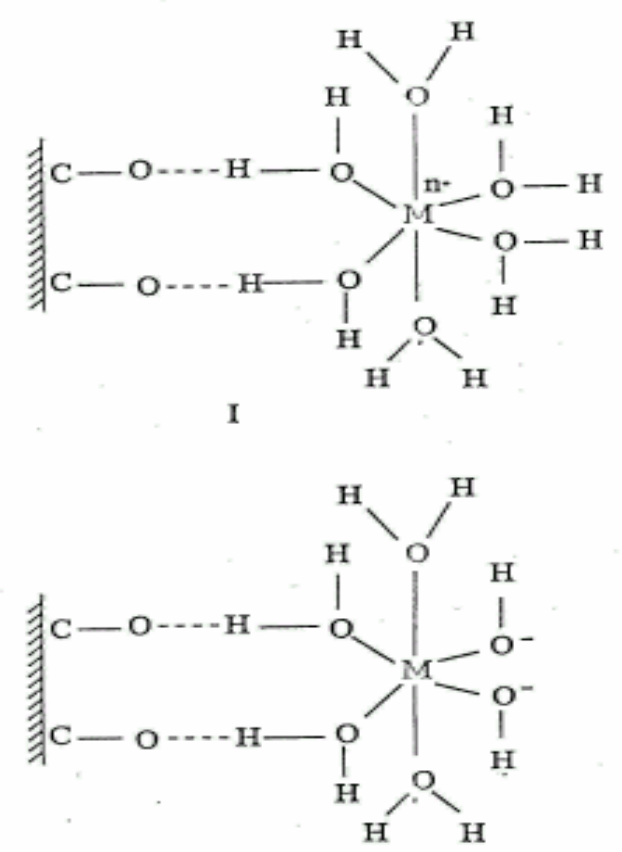



II

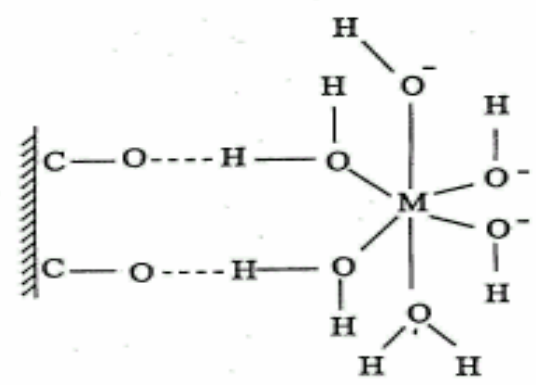

In conclusion, The presence of different metal oxides in ash content of RS-5, commonly $\mathrm{SiO}_{2}$ and surface oxygen functional groups on the carbon content makes the adsorption of metal ions on the surface of RS- 5 occurs with different mechanisms as ion exchange and metal complex formation. Ion exchange mechanism is the common one. 


\section{CONCLUSION}

Enriched $\mathrm{Zn}^{+2}$ and $\mathrm{Cd}^{+2}$ have a high cost and used in the preparation of targets for production of $\left({ }^{67} \mathrm{Ga}\right.$ and $\left.{ }^{111} \mathrm{In}\right)$, so Recovery process is very important to reuse $\mathrm{Zn}^{+2}$ and $\mathrm{Cd}^{+2}$ which are found in the waste of Egypt's Cyclotron radioisotopes production units $\left({ }^{67} \mathrm{Ga}\right.$ and $\left.{ }^{111} \mathrm{In}\right)$. Adsorption process is the most economic method in the recovery of $\mathrm{Zn}^{+2}$ and $\mathrm{Cd}^{+2}$ and so agro-residues may be converted into novel sorbents suitable in purification or separation of metal ions. The removal of metal ions is dependent on the $\mathrm{pH}$ of the solution, carbon dose, sorption medium type and initial concentration of the metal ions and the adsorptive capacity shows that the most effective sorbent is (RS-5). The mechanism of metal uptake proceeds through the ion-exchange by deprotonation of silanol group and through chemical binding with oxygen surface groups of (RS-5) sorbent.

\section{REFERENCES}

[1] Gadde, R. R. and Laitinen, H. A., "Studies of heavy metal adsorption by hydrous iron and manganese oxides" Analytical Chemistry, 46 (13), 2022 (1997).

[2] Gray, M. J. and Malati, M. A., "Adsorption from aqueous solution by $\delta$ manganese dioxide II. Adsorption of some heavy metal cations" J. Chem. Tech. Biotechnol., 29, 135 (1999).

[3] Korkisch, S. L. "Modern Methods for the Separation of Rare Metal Ions" Pergamon Press, New York, (1989).

[4] Kunin, R. A., "Elements of lon Exchange" Reinhold, New York, (1990).

[5] Koshima, H. and Onishi, H., "Collection of Mercury from artificial sea-water with activated carbon" Talanta, 27, 795 (1980).

[6] Iley, M., Marsh, H. and Rodriguez-Reinoso, F., "The adsorptive properties of carbonized olive stones", Carbon, 11, 633 (1993).

[7] Linares-Solano, A., Lopez-Gonzalez, J. D.; Molina-Sabio, M. and Rodriguezreinoso, F., "Active carbons from almond shells as adsorbents in gas and liquid phases" J. Chem. Tech. Biotechnol., 30, 65 (1980).

[8] Rivera-Utrilla, J. and Ferro-Garcia, M. A., "Studies on the adsorption of cesium, thallium, strontium and cobalt radionuclides on activated carbons from aqueous solutions" J. Chem. Tech. Biotechnol., 34(A), 24 (1984).

[9] Seco, A., Marzal, P. and Gabaldon, C. "Adsorption of heavy metals from aqueous solution onto activated carbon in single $\mathrm{Cu}$ and $\mathrm{Ni}$ systems and in binary Cu-Ni, Cu-Cd and Cu-Zn systems" J. Chem. Tech. Biotechnol., 68, 23 (1997).

[10] Vallee, B. L. "Zinc biochemistry and phsiology and their derangements in New Trends in Bio-inorganic chemistry" Acadmic Press, New York 11 (1988).

[11] Rajakovic, L. V. and Mitrovic, M. M. "Arsenic removal from water by chemisorption filters" Environ. Pollut., 75 (3), 279 (1992).

[12] Das, N. C. and Bandyopadhyay, M. "Removal of copper (II) using Vermiculite" Water Environ. Res., 64, 852 (1992) 
[13] Hao, O. J., Tsai, C. M. and Huang, C. P. "The removal of metals and ammonium by natural Glauconite" Environ. Int., 13, 203 (1987).

[14] Huang, C. P. and Vane, L. M. "Enhancing $\mathrm{As}^{5+}$ removal by a $\mathrm{Fe}^{2+}$ treated activated carbon" J. Water Pollut. Control Fed., 61 (9-10), 1596 (1989).

[15] Comba, P., Dahnke, D. R. and Twidwell, L. G. "Removal of arsenic from process and waste water solutions", "Proceedings of the Symposium on Arsenic Metallurgical" Phoenix, Arizona, The Metallurgical Society, Inc., Pennsylvania, USA (1988).

[16] Schlicher, R. J. and Ghosh, M. M. "Removal of arsenic from water by physicalchemical processes, separation of heavy metals and other trace elements" AlchE Symposium Series, American Institute of Chemical Engineering, New York (1985).

[17] Pahlavanpour, B., Thompson, M. and Thorne, L. "Simultaneous determination of trace concentrations of Arsenic, Antimony and Bismuth in soils and sediments by volatile hydride generation and inductively coupled plasma emission spectrometry" Analyst, 105, 756 (1980).

[18] Nakahara, T. "Application of hydride generation to the determination of trace concentrations of Arsenic by inductively coupled plasma atomic emission spectrometry" Anal. Chim. Acta, 131, 73 (1981).

[19] Lee, J. K. and Rosehart, R. G. "Effective methods of arsenic removal from gold mine wastes", Fourth Annual Meeting of the Canadian Mineral Processors, Ottawa, Canada, 107-128 (1972).

[20] Streat, M. and Horner, D. J. "Adsorption of highly soluble herbicides from water using activated carbon and hyper cross linked polymers" Transactions of the Institution of Chemical Engineers, part B, Process Safety and Environmental Protection, 78 (B5), 363 (2000).

[21] Tai, M. H., Saha, B. and Streat, M. "Characterization and sorption performance of a Hypersol-Macronet polymer and an activated carbon" Reactive and Functional Polymers, 41, 149 (1999).

[22] Gabaldon, C., Marzal, P., Ferrer J. and Seco, A. "Single and competitive adsorption of $\mathrm{Cd}$ and $\mathrm{Zn}$ onto granular activated carbon" Wat. Res., 30 (12), 3050 (1996).

[23] Tai, M. H. and Streat, M. "Sorption of cationic species on acid and air oxidized carbons" Proceedings of Euro Carbon Conference, July 5-9, Strasbourg, France, 287 (1998).

[24] EDWIN VASU, A. " Adsorption of $\mathrm{Ni}(\mathrm{II}), \mathrm{Cu}(\mathrm{II})$ and $\mathrm{Fe}(\mathrm{III})$ from Aqueous Solutions Using Activated Carbon", E-Journal of Chemistry, 5 (1), 1 (2008). 


\section{니ST OF TABLES}

Table (1). Chemicals and Reagents used in Experimental Work.

\begin{tabular}{|c|c|c|c|}
\hline Name & Formula & M.Wt & Product of \\
\hline Hydrochloric acid & $\mathrm{HCl}$ & 36.50 & Sigma \\
\hline Ammonium chloride & $\mathrm{NH}_{4} \mathrm{Cl}$ & 53.49 & Sigma \\
\hline Zinc chloride & $\mathrm{ZnCl}_{2}$ & 136.2 & Riedel-de Haen \\
\hline Cadmium chloride & $\mathrm{CdCl}_{2}$ & 183.3 & Sigma \\
\hline Sodium hydroxide & $\mathrm{NaOH}$ & 40.02 & Sigma \\
\hline Nickel chloride & $\mathrm{NiCl}_{2}$ & 129.6 & Sigma \\
\hline
\end{tabular}


Table (2) pH and $x$ Values of Zinc, Cadmium and Nickel Solutions.

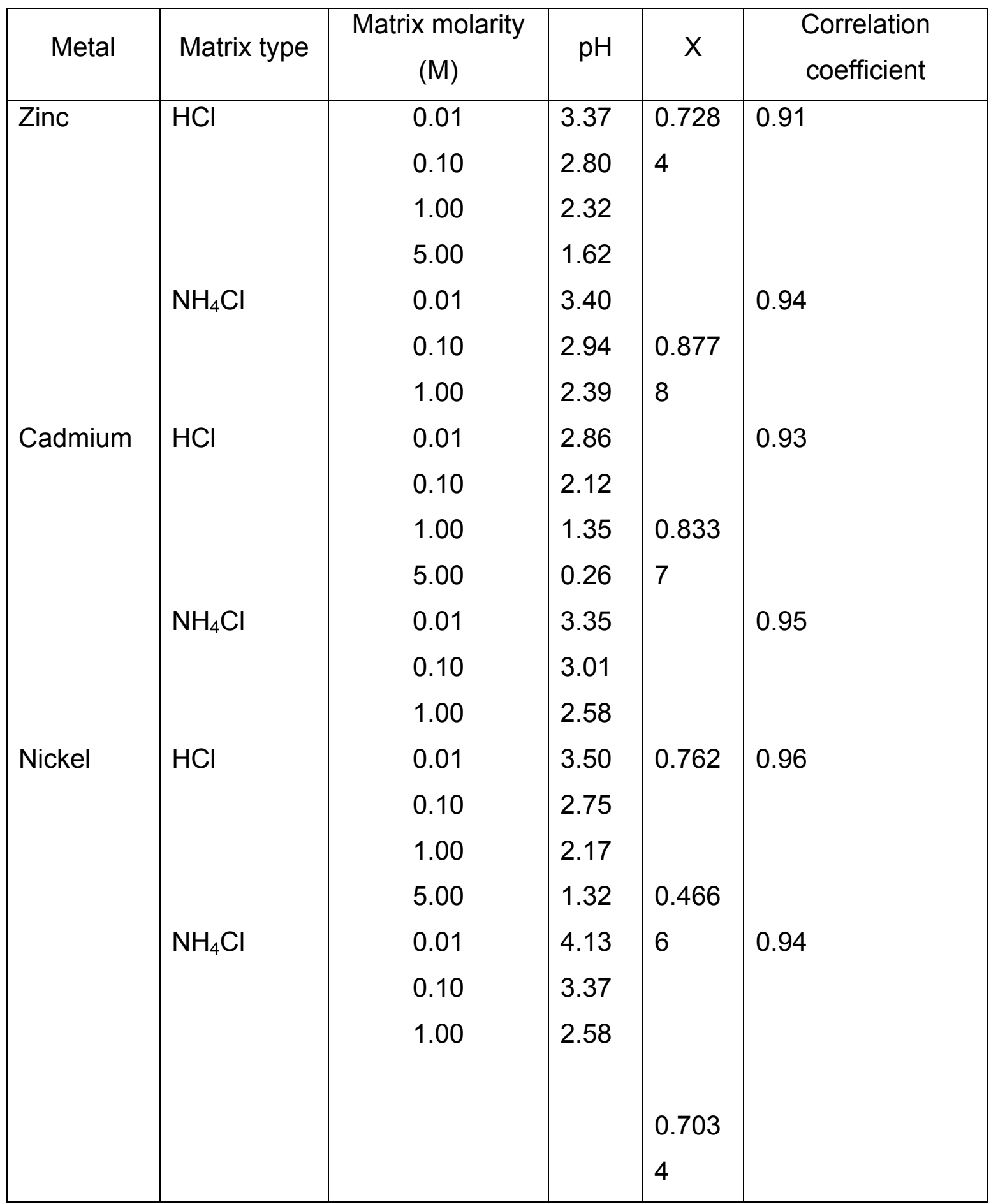




\section{니ST OF FIGURES}

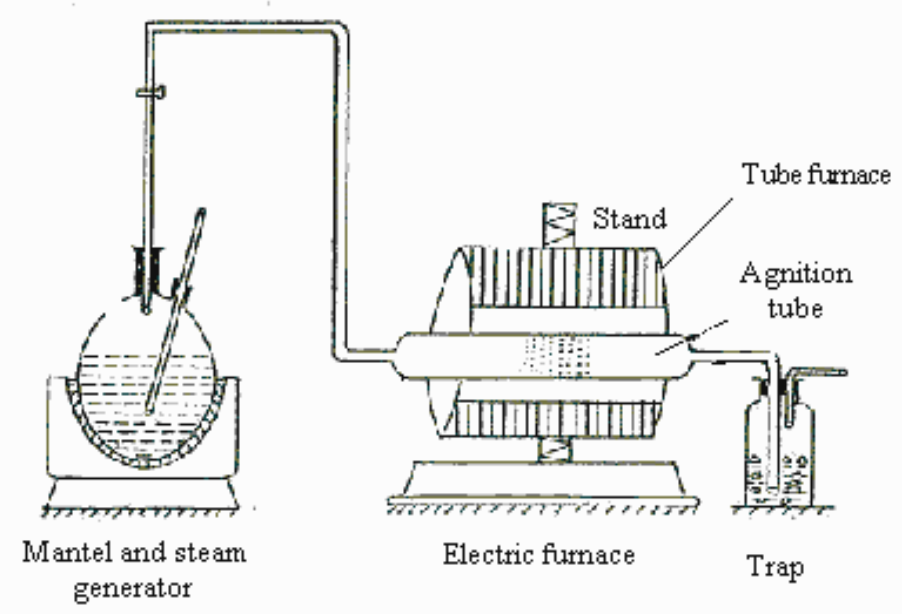

Fig. 1. Schematic diagram of the system used for the preparation of one-step steam activated carbon 


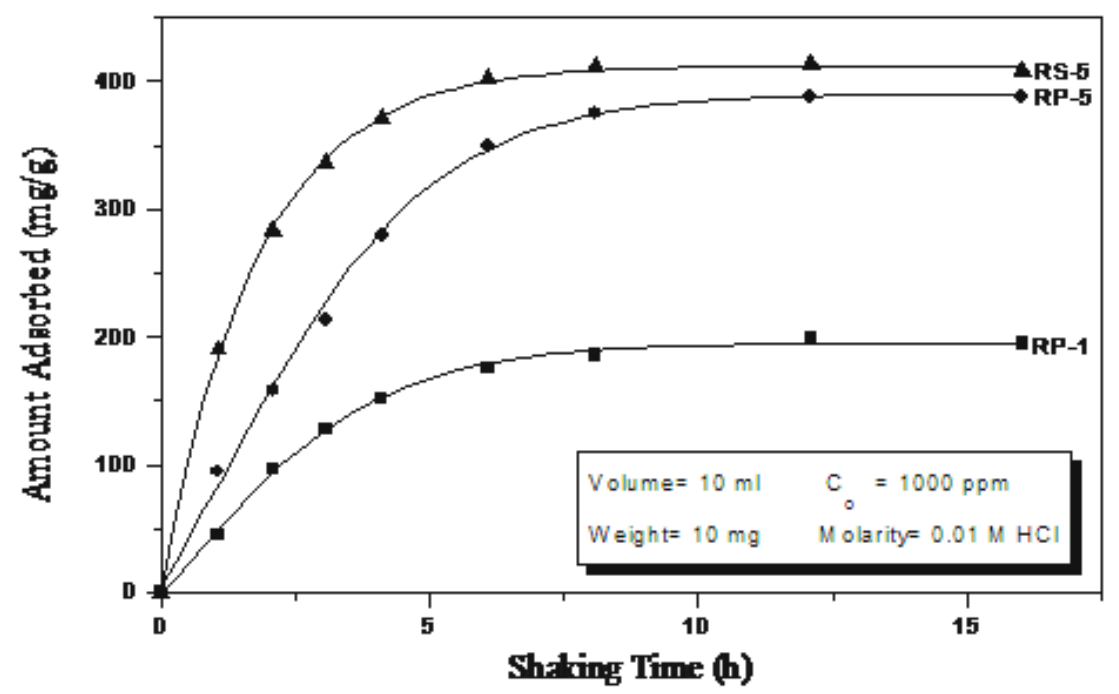

Fig. 2. Fffect of aisorbent type on aisoption of $\mathrm{Z}^{+2}$ ion at 0 .01MHC



Fig.. 3. Effect of aisorbent type on aksomtion of $\mathrm{Zn}^{+2}$ ion a $0.1 \mathrm{M} \mathrm{HC}$. 


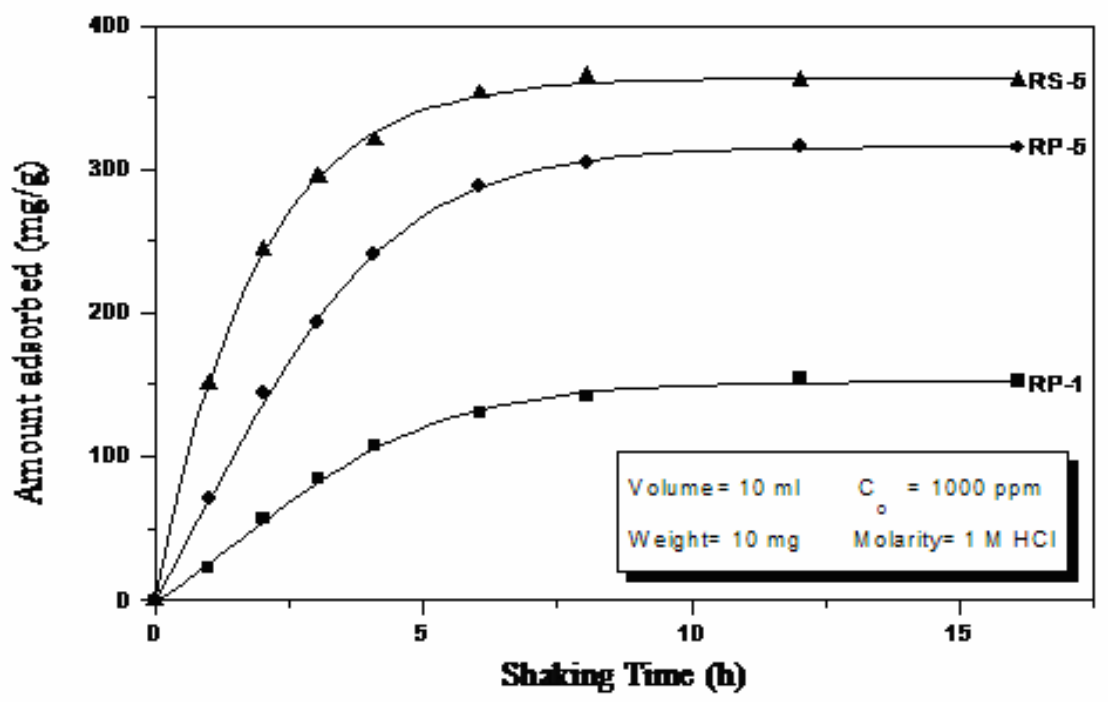

Fig. 4. Effect of adsurbent type on aisorption of $\mathrm{Zn}^{+2}$ ion at $1 \mathrm{M}$ HCL



Fi g. 5. Effect of aisorbent type on adsorption of $\mathrm{Cd}^{+2}$ ion $\pm 0.01 \mathrm{M} \mathrm{HCl}$ 


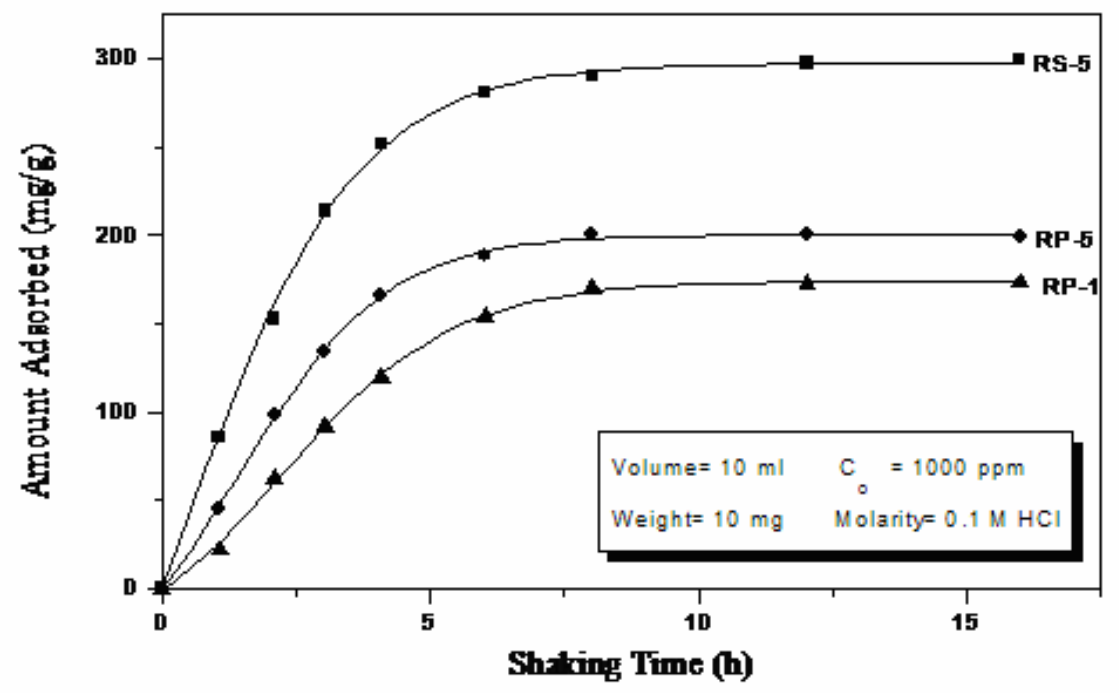

Fig. 6. Effect of adsorbent type on aisorption of Ca+2 ion at $0.1 \mathrm{M} \mathrm{HC}$

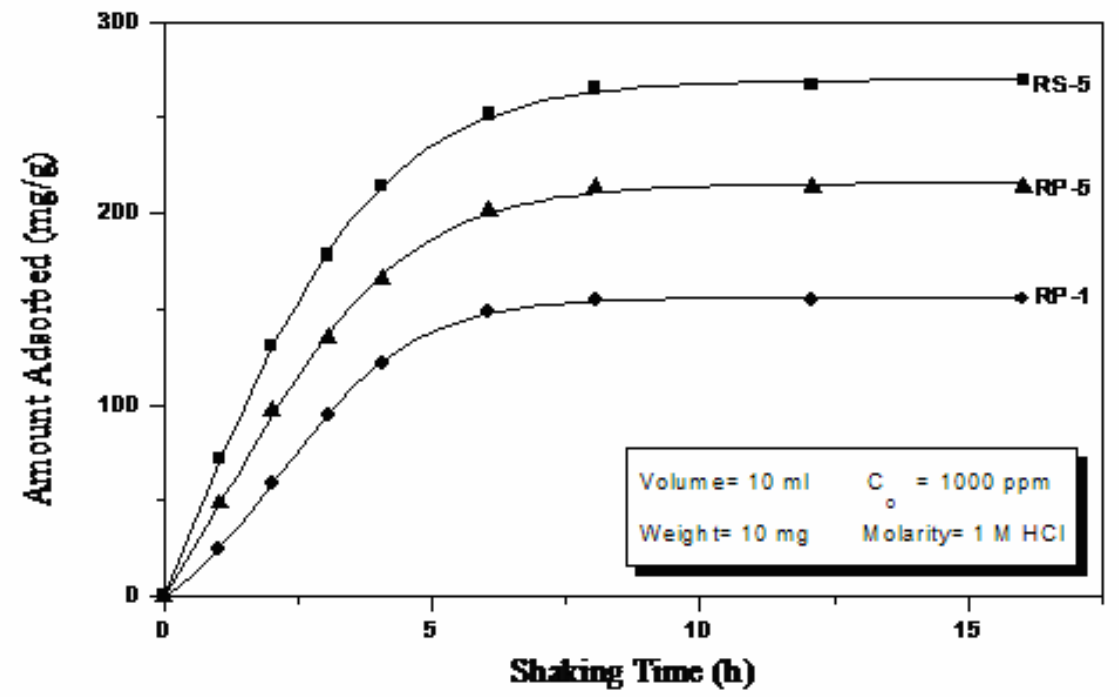

Fig. 7. Effect of adsurbent type on adsorption of Cd+2 ion at 1 MHCl 


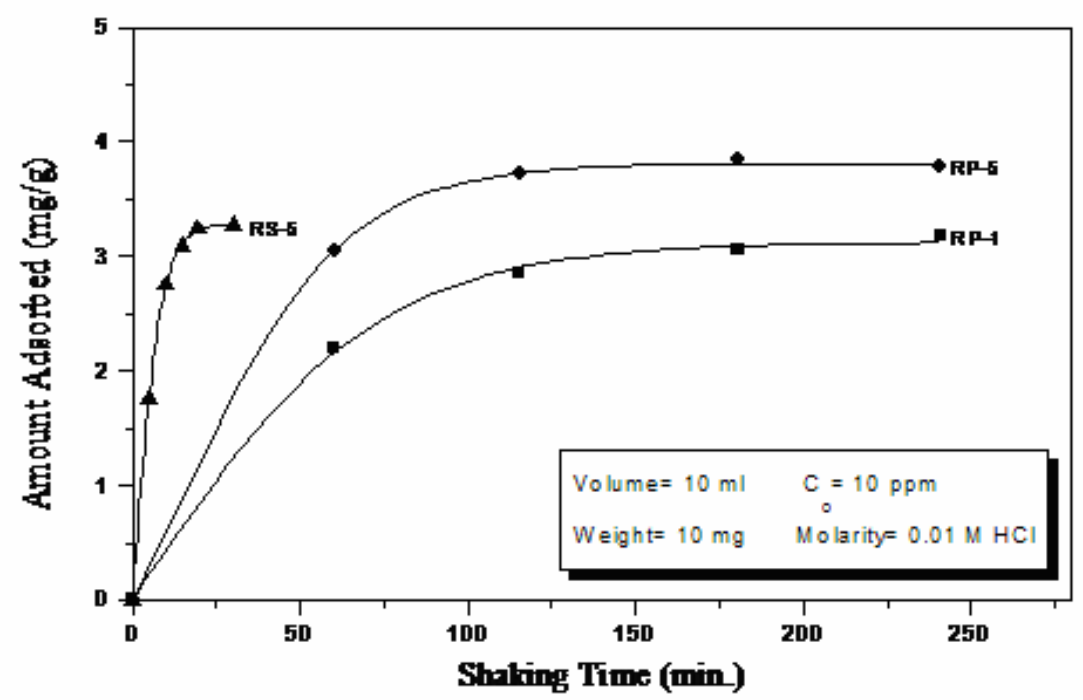

Fig. 8. Effect of aisorbent type on aisorption of $\mathrm{Ni}^{+2}$ ion at 0_01M HCl



Fig. 9. Effect of adsobent type on adsoption of $\mathrm{N}+2$ ion $\neq 0.1 \mathrm{MHC}$ 


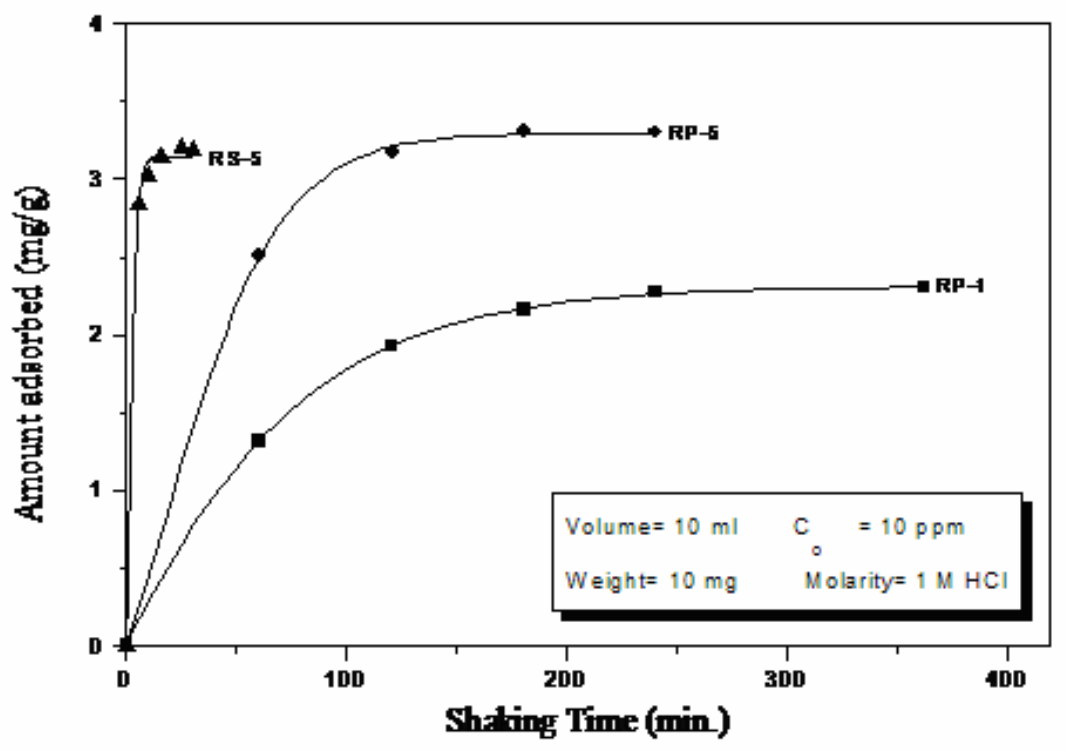

Fig.10. Effect of adsorbent type on adsoption of $\mathrm{Ni}^{+2}$ ion at $1 \mathrm{MHC1}$

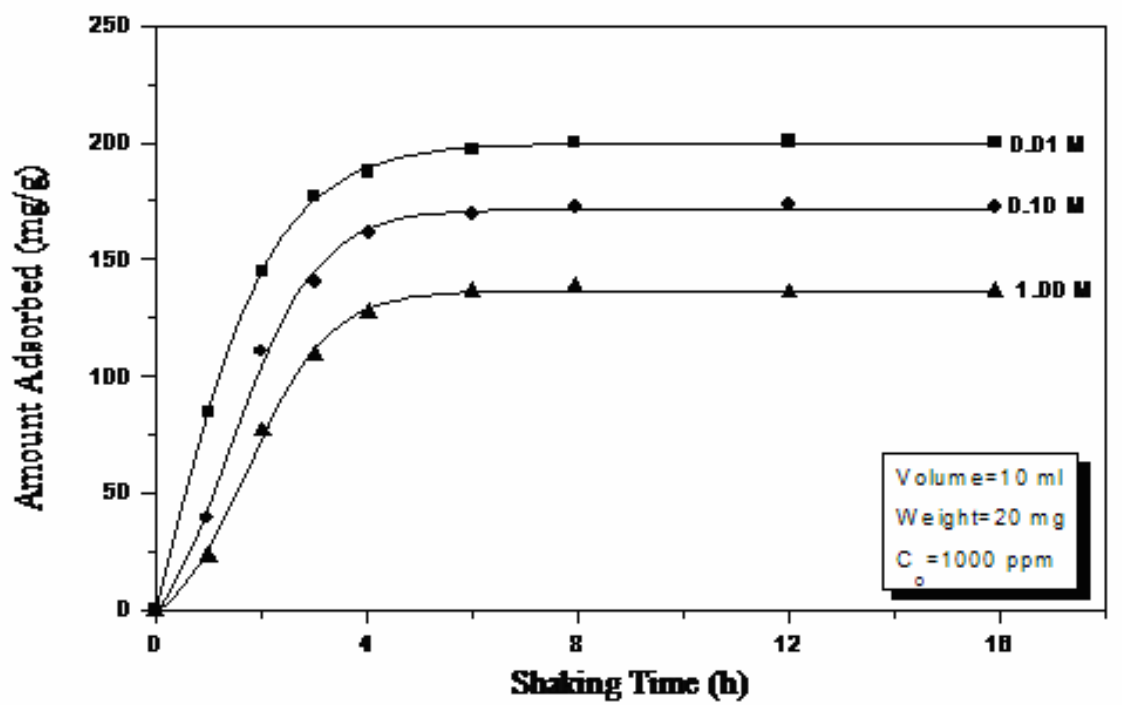

Fig. 11. Effect of shaling time on adsoption of $Z \pi^{+2}$ ion at different HCl mol-rities on'm surbent (RP-1) 


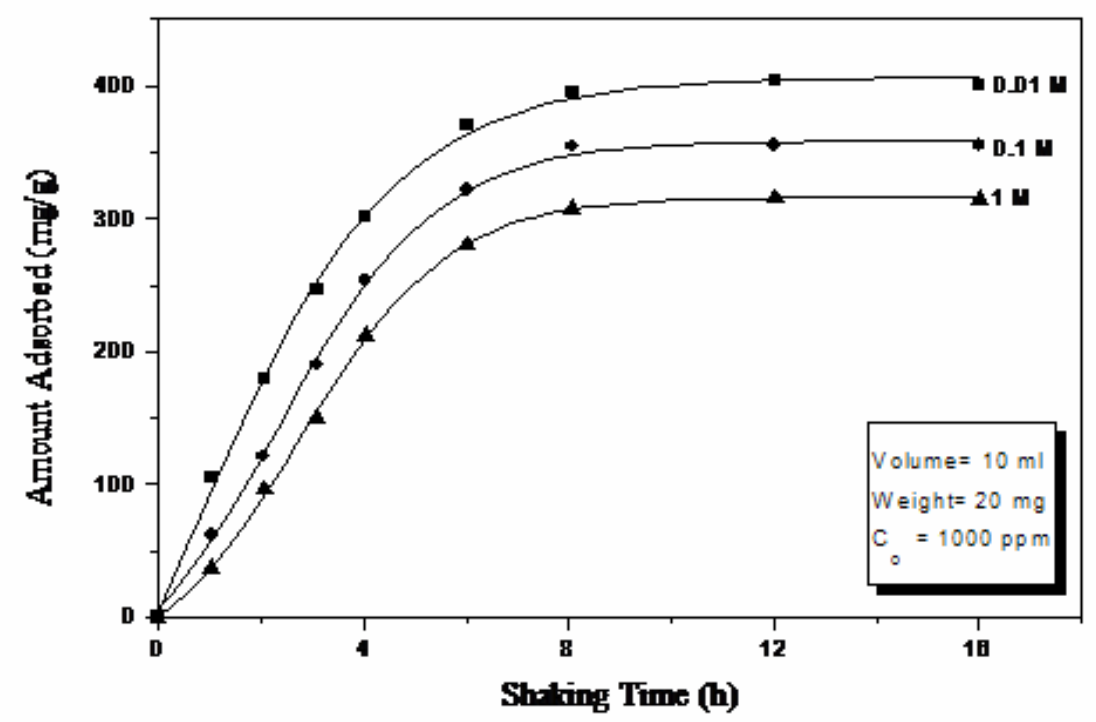

Fig. 12. Efiect of shring time on alsorption of $\mathrm{Zn}^{+2}$ ion at ifferent HC molarities onto sorbent (RP-S)



Fig. 13. Effect of shaling time on alsortion of $\mathrm{Zn}^{+2}$ ion at dfferent HC1 molanities onto sobent (RS-5) 


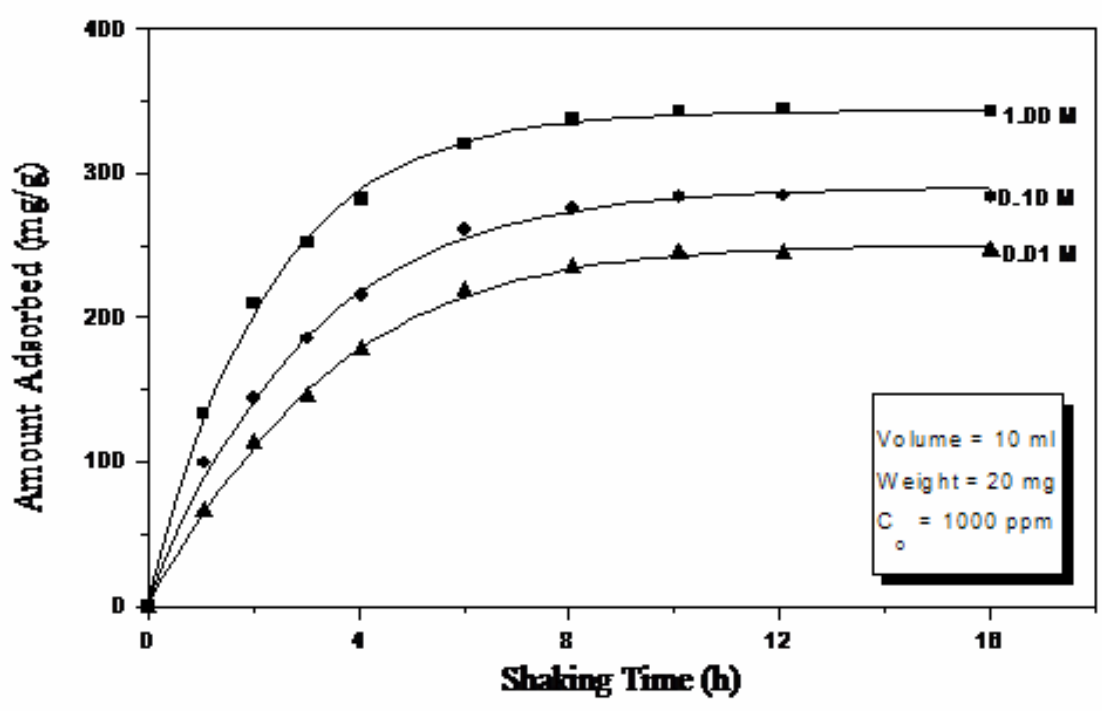

Fig. 14. Effect of shaling time on alsoption of $\mathrm{n}^{+2}$ ion at different NH C1 molarities onto sombent (RS-5)

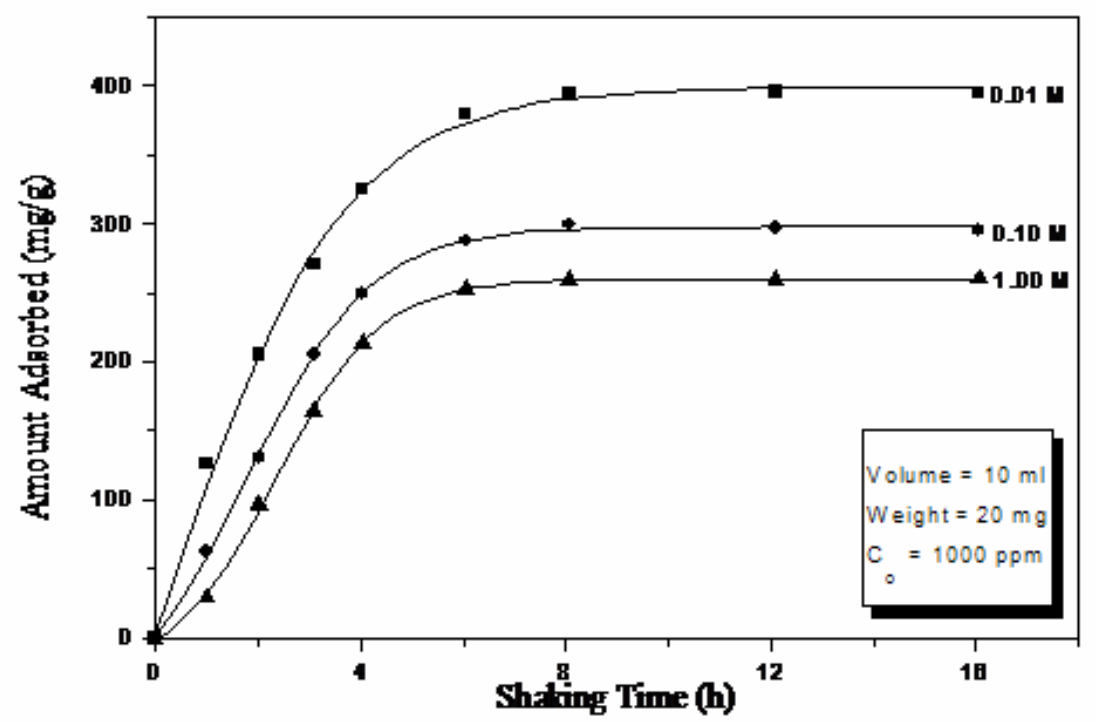

Fig. 15. Effect of shaling time on alsoption of $\mathrm{Cd}^{+2}$ ion at dfferent HC1 molarities anto sarbent (RP-1) 


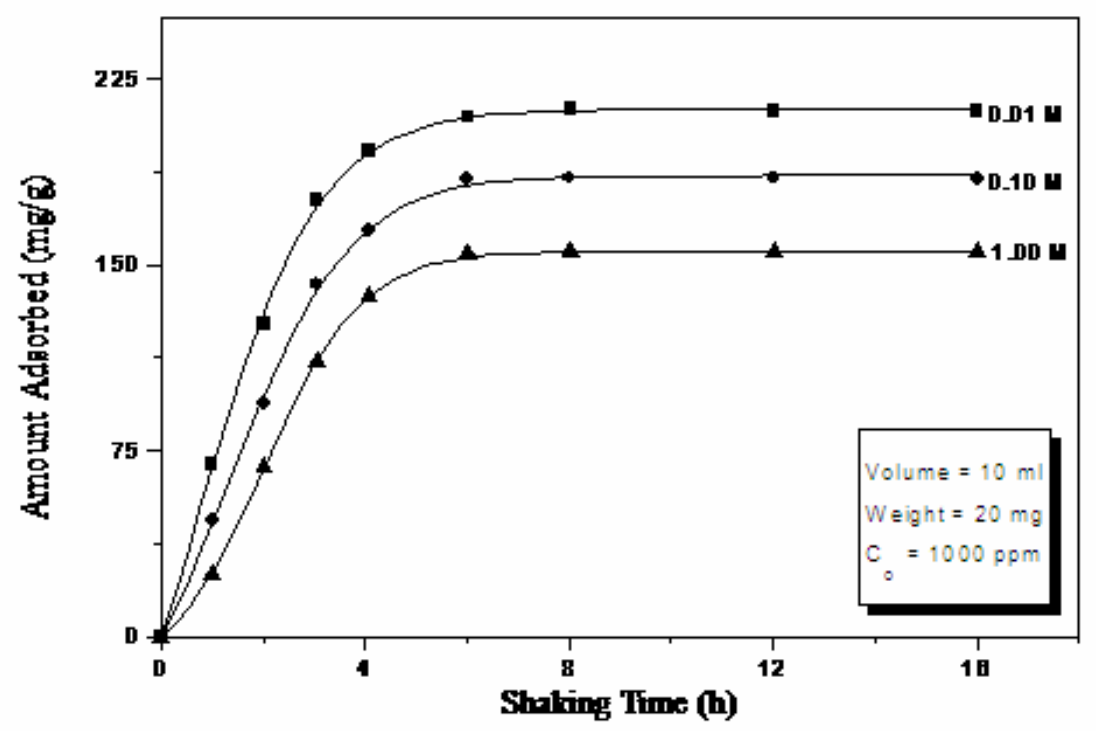

Fig. 16. Efiect of sh-ing time an adsoption of $\mathrm{C}^{+2}$ ion $\pm t$ difierent HCl molrities on'm sotbent (RP-5)

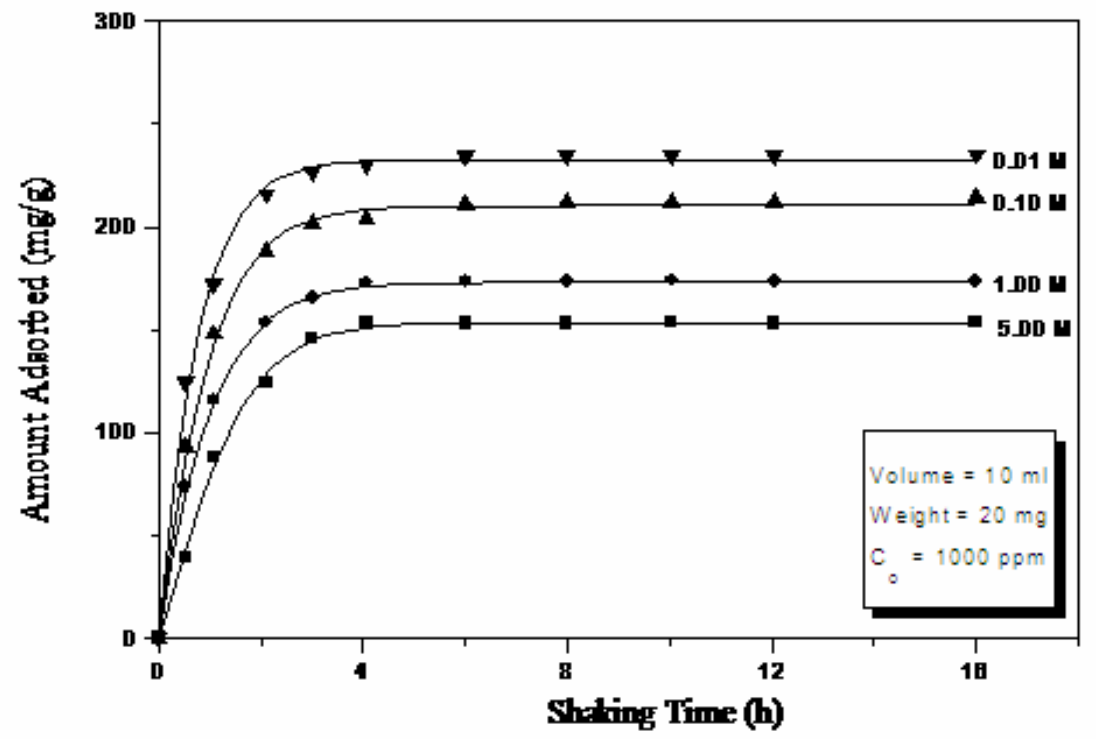

Fig. 17. Effect of shaling time on alsoption of $\mathrm{Cl}^{+2}$ ion at different HO molarities anto sabent(RS-5) 




Fig. 18. Effect of sheting time on adsorption of Cd+2 ion at dfferent NH C1 molarities onto subent (RS-5)

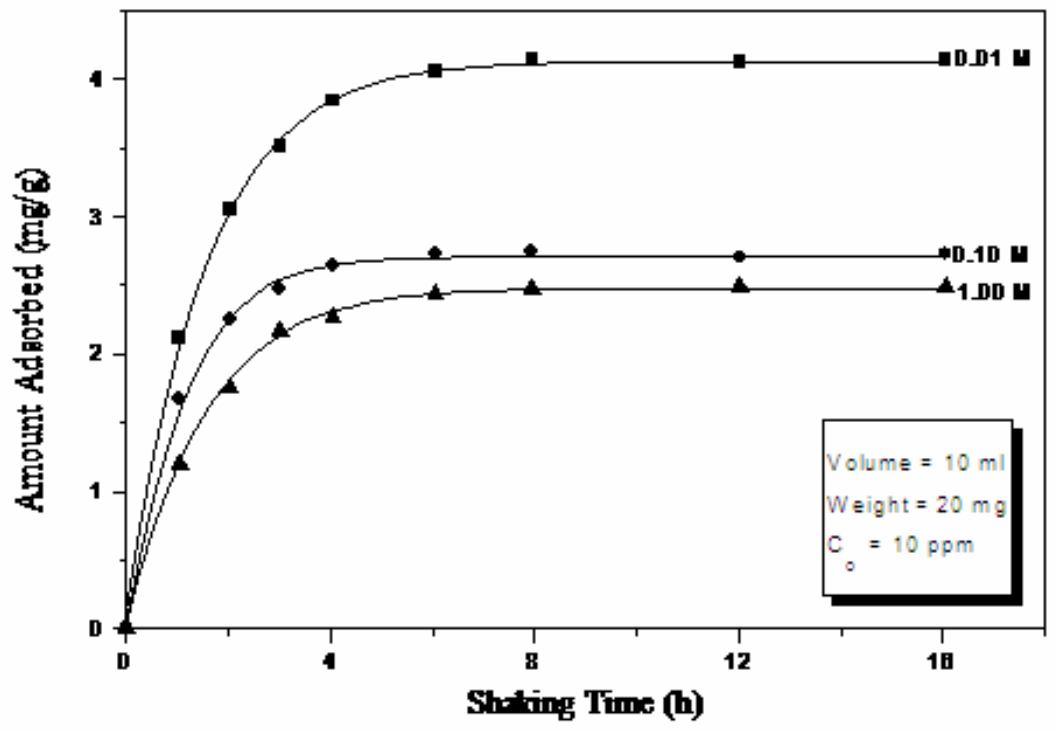

Fig. 19. Efiect of shting time on adsoption of $\mathrm{N}^{+2}$ ion at different HCl malarities on'n surbent (RP-1) 


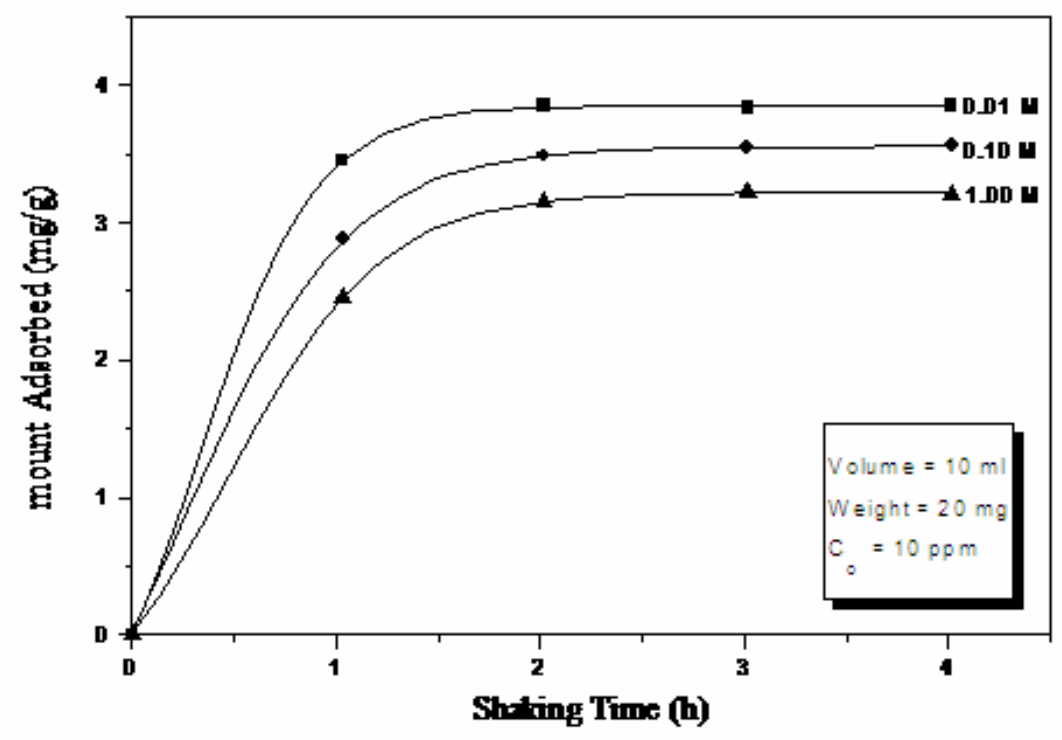

Fig. 20. Efiect of shring time on alsoption of $\mathrm{Ni}^{+2}$ ion at different HC molarities antn sorbent (RP-5)

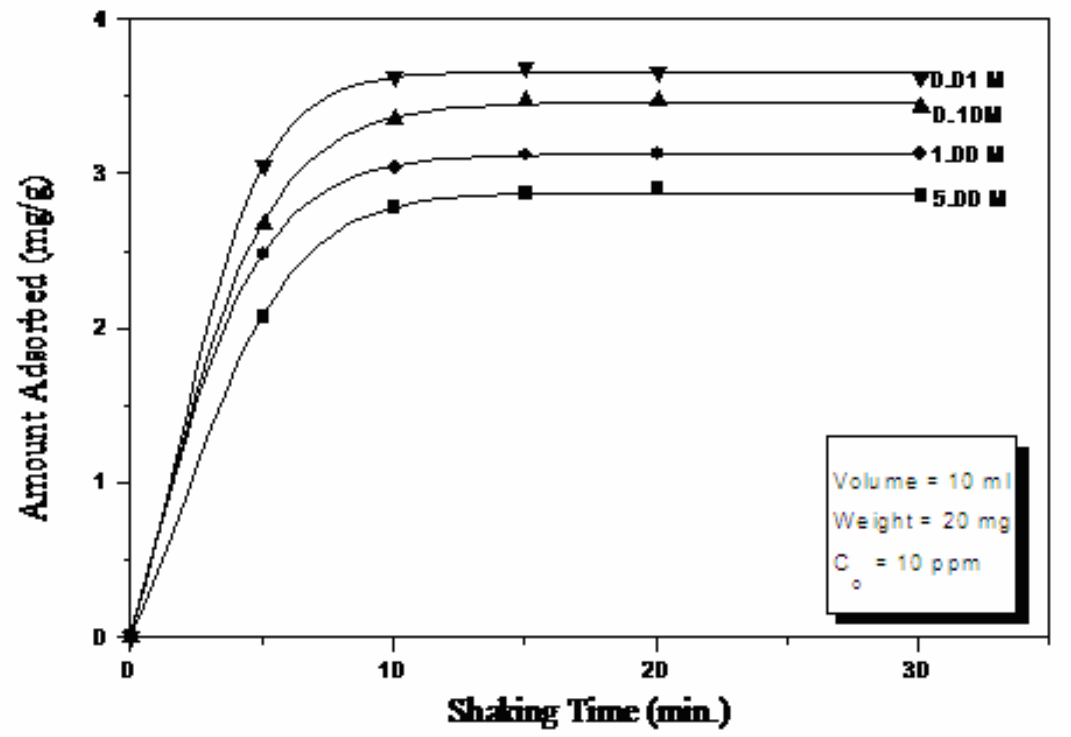

Fig. 21. Effect of shaing time on alsoption of $\mathrm{Ni}^{+2}$ ion at dfferent HO molanities anto sabent (RS-5) 




Fig. 22. Effect of shrting time on alsorption of $\mathrm{Ni}^{+2}$ ine at ifferent NH CI molanities on'n adsorbent (RS-5)



Fig. 23. Effect of $\mathrm{pH}$ on the adsorption of $\mathrm{Zn}^{+2}$ on'm sorbentRS-5 


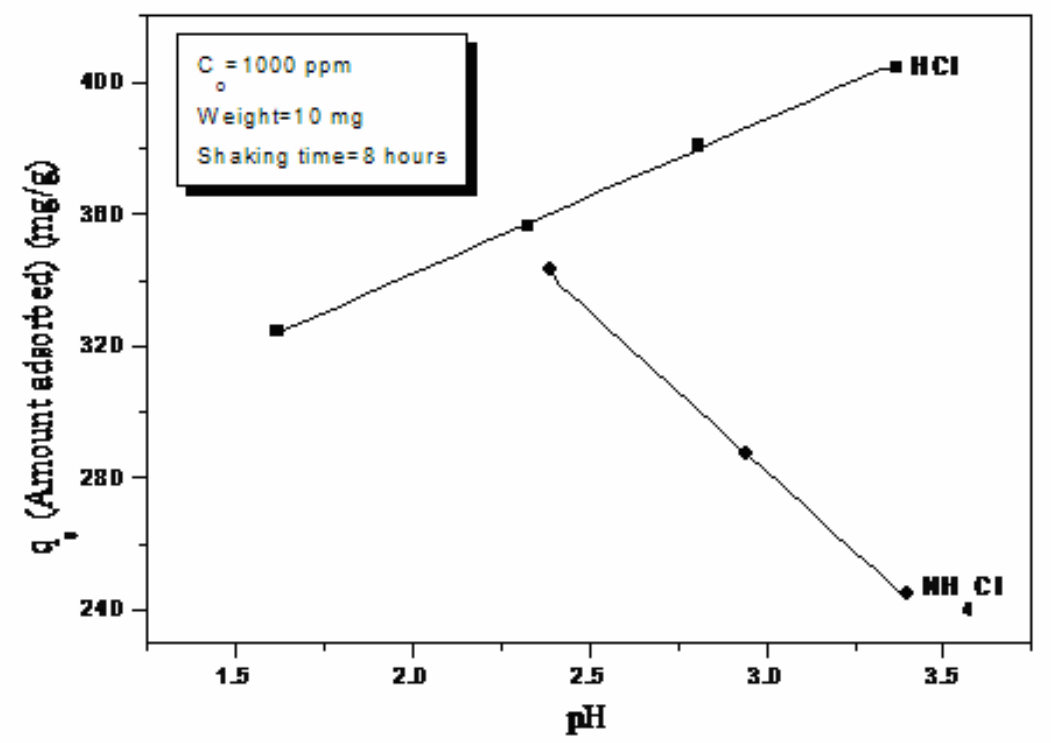

Fig. 24. Effect of $\mathrm{pH}$ on the alsorption of $\mathrm{Zn}^{+2}$ onto sorbentRS-5

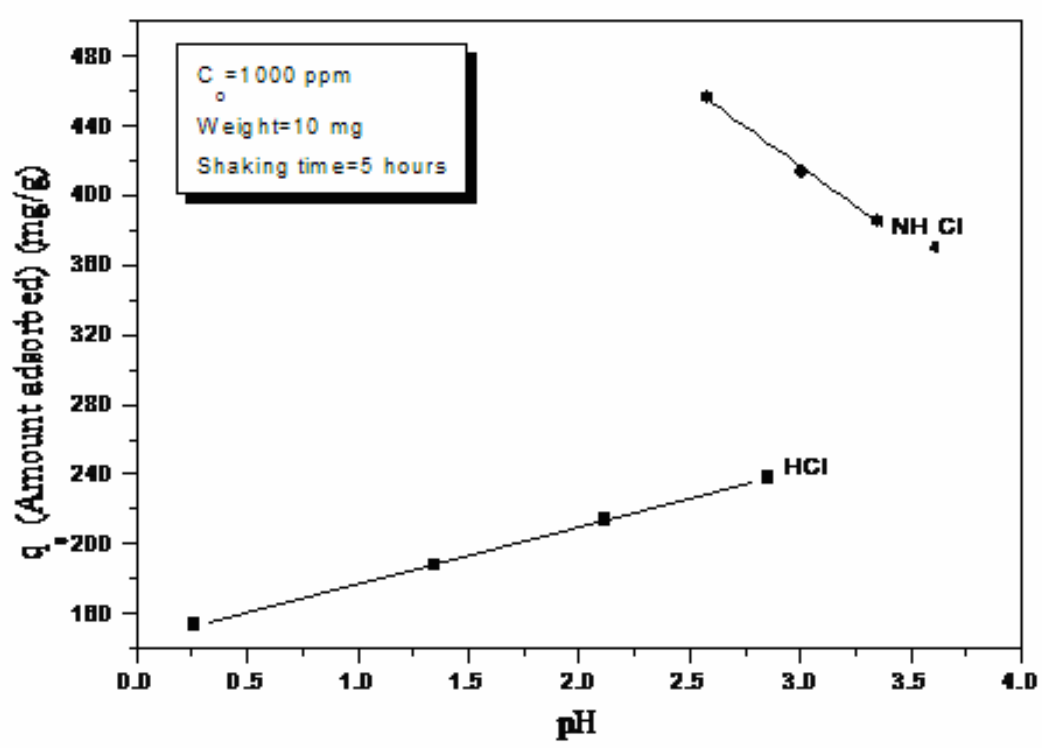

Fig. 25. Effect of $\mathrm{pH}$ on the aisorption of $\mathrm{Cd}^{+2}$ onto sorbentRS-5 


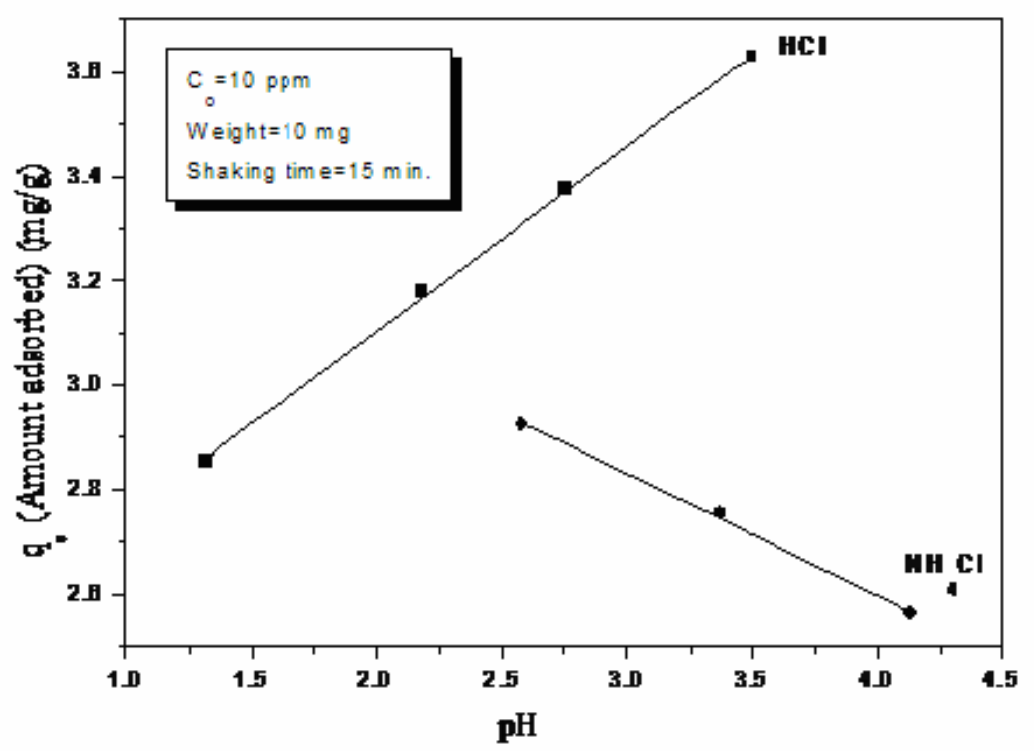

Fig. 26. Effect of $\mathrm{pH}$ on the alsorption of $\mathrm{Ni}^{+2}$ anto soubent $\mathrm{RS}-5$ 